\title{
Uptake and utilization of institutional voluntary HIV testing and counseling services among students aged 18-24 in Kenya's public Universities
}

\author{
Caliph Cheruiyot ${ }^{1}$, Dennis Magu ${ }^{1}$, Patrick Mburugu², Daniel Sagwe ${ }^{3}$
}

1. Jomo Kenyatta University of Agriculture and Technology, Environmental health and Disease control.

2. Jomo Kenyatta University of Agriculture and Technology, Paediatrics and Child Health.

3. Jomo Kenyatta University of Agriculture and Technology, Rehabilitative Sciences.

\begin{abstract}
Background: Kenya is home to an estimated 1.7 million people living with HIV/AIDS. According to the Kenya AIDS Indicator survey KAIS 2012, HIV prevalence in the age group 15-24 stood at 2.2\%. Globally, young people aged 15-24 are a highly vulnerable population with respect to HIV/AIDS infection and transmission. HIV testing and counseling services play a critical role as an entry point to care and treatment. However, uptake of HIV testing and counseling services among the youth in Kenya has been reportedly low. Youths at Universities are among the priority populations in HIV/AIDS programs.

Objectives: This study aimed to determine the barriers to uptake and utilization of institution-based voluntary counseling and testing VCT services among students aged 18-24 in selected public universities in Kenya. The specific objectives were to determine the factors associated with uptake and utilization and the association between various socio-demographic factors and service uptake in institutional VCT facilities.
\end{abstract}

Methods: This research utilized a descriptive cross-sectional study design where primarily, data was collected using semi-structured questionnaires and through focus group discussions held with the students in the sampled Universities. Data available at Jomo Kenyatta University of Agriculture and Technology JKUAT Hospital VCT were reviewed for the period 2010 and 2016 to give an insight into service utilization rates among students. Multi-stage sampling technique was utilized to reach a student sample size of 305 from the selected public Universities in Kenya.

Results: Uptake of institutional VCT services among University students sampled stood at $45 \%$ from a population where $84.4 \%$ were aware of the presence of these services on their campuses. More males than females utilized the services. Emerging themes from the study indicated that participants utilized the services for different reasons. Accessibility to test site, testing hours, fear to be seen at site and fear of test result were also identified as factors affecting service uptake. These factors also were also reported when students were asked about their desired characteristics of a VCT facility on campus.

Conclusion: This study has unraveled the factors that are associated with testing and counseling in institutional facilities. University students seem to seek and utilize VCT services for different reasons. It is also clear that patterns of services utilization vary from group to another as observed in the case of year of study, gender and age category.

Recommendations: It is necessary for policy makers in institutions of higher learning together with those tasked with managing healthcare services in these institutions to adopt approaches that will overcome the barriers to utilization of VCT services among students. With knowledge of the factors associated with uptake and utilization of VCT services in institutional facilities, efforts to tackle the barriers and maximize on enhancers should be utilized fully in order to improve uptake and utilization of services. More research should also focus on the persisting risky sexual behaviors among University students despite the high knowledge they have on HIV/AIDS.

Keywords: Higher learning institutions, voluntary counseling and testing, HIV, barriers and uptake.

DOI: https://dx.doi.org/10.4314/ahs.v19i4.42

Cite as: Cheruiyot C, Magu D, Mburugu P, Sagwe D. Uptake and utilization of institutional voluntary HIV testing and counseling services among students aged 18-24 in Kenya's public Universities. Afri Health Sci.2019;19(4):3190-3199.https:/ / dx.doi.org/10.4314/ abs.v19i4.42

\section{Corresponding author: \\ Caliph Cheruiyot, Jomo Kenyatta University of Agriculture \\ and Technology, Environmental health \\ and Disease control. \\ Email: xkirca@yahoo.com}

\section{Introduction}

Since the beginning of the HIV/AIDS epidemic, more than 78 million people worldwide have been infected and approximately 35 million have died from AIDS-related illnesses. The number of people infected with HIV globally was estimated at 34 million by the end of 20101 of whom 12.5 million were young people aged 15-24 years ${ }^{1}$. 
Sub-Sahara Africa is the most seriously affected region where an estimated $45 \%$ of all new HIV infections occur in the age group 15-24 years ${ }^{2}$, and AIDS being the leading cause of death ${ }^{3}$. Despite reductions in new infections, prevalence rates and an increased coverage of those who need ARV drugs in sub-Saharan Africa, the numbers of those infected are still quite high ${ }^{4}$.

With an estimated 1.7 million people living with HIV and AIDS, Kenya is one of the countries in the Sub-Sahara region that has been hardly hit with estimates of a national prevalence of $6 \%$ during the year $2013^{5}$. The report further indicated that there were approximately 1.6 million people living with HIV in the country, with 50,000 AIDS related deaths and about 100,000 new HIV infections that year.

The HIV/AIDS pandemic is posing big challenges for the academic institutions too since the infection is currently killing young economically productive people thus depriving the country of a qualified and productive labor force ${ }^{6}$. However, they can also serve as points of HIV transmission since they largely constitute a potentially fertile breeding ground for the infection ${ }^{7}$. The rise of transactional and inter-generational sex, predation and multiple sexual partners is reportedly a big challenge among university students ${ }^{8}$. This has fuelled the further spread of the infection in this highly productive population. Study findings from UNAIDS show that about $50 \%$ of all new HIV infections are in young people aged 15$24^{9}$. Another study in Kenya showed that approximately $29 \%$ of all new HIV infections are among the adolescents and the youth, a group that makes up about $19 \%$ of the Kenyan population.

University-going students are a high risk population with respect to HIV/AIDS infection ${ }^{10}$. This is majorly attributed to early sexual debut, inconsistent use of condoms, high number of sexual and concurrent partners, intergenerational sex and the abuse of drugs and alcohol. HIV testing and counseling services serve as a very important entry point to HIV\&AIDS care and treatment ${ }^{11}$. Most HIV prevention programs rely on knowledge of one's HIV status as a key starting point. Among the facilities that play a key role in HIV prevention are VCT facilities. VCT's have mostly been used as sexual behavior change catalysts as well as serving as entry points to care and treatment. These facilities in institutions of higher learning are therefore important in the fight against the epidemic in this highly sexually active population. Past research has identified three categories of factors that can influence the utilization of VCT services namely need, predisposing and enabling factors. This study therefore aimed to determine the factors associated with uptake and utilization of institutional VCT services among students aged 18-24 in Kenya's public Universities and the associations between various socio-demographic factors and service uptake.

\section{Study hypothesis}

This study assumed that there are barriers to utilization of institutional VCT services among students aged 18-24 in Kenya's public Universities.

\section{Gaps in knowledge}

Whereas several studies have focused on the factors associated with utilization of VCT services among young people, no study has attempted to investigate the factors that affect VCT utilization among University students in VCT facilities set up specifically for them on campus.

\section{Statement of the problem}

University education in Kenya has become increasingly and widely accessible to many, with the government gradually lowering the entry grades for government-sponsored students as well as several new campuses being set up across the country. HIV and AIDS affects the university population equally as it does any other community. University health services play a great role in ensuring and improving the health of the university community. Integration of HIV testing and counseling services into the university health services has therefore become an important priority in institutions of higher learning in Kenya. These Universities largely comprise of young people at the peak of sexual activity and experimentation. In a study conducted among 923 students at the University of Nairobi, nearly 30\% reported having had multiple partners in the previous 12 months, $27.4 \%$ of them did not use condoms with sexual partners and $21 \%$ engaged in sex after drinking ${ }^{12}$. In a previous HIV/AIDS assessment from a representative sample of 1,917 university students at Moi University in Eldoret, 89\% of students reported thinking they were at risk for HIV infection, but only $28 \%$ of subjects had been tested for HIV. Sexual activity on campus was reportedly high and many students considered themselves at risk. Conversely, consistent con- 
dom use and rates of voluntary counseling and testing were low ${ }^{13}$.

Despite increased knowledge on HIV/AIDS among the young people, uptake and utilization of HIV testing and counseling services among them has been reportedly low. The prevalence of HIV counseling and testing among young people in the country is low, standing at 33.6\% and $49.6 \%$ among males and females respectively aged 15-24 years ${ }^{14}$. There was therefore a great need to investigate the factors associated with VCT service uptake and utilization among students aged 18-24 in Kenya's public Universities.

\section{Justification}

Study findings from UNAIDS show that about $50 \%$ of all new HIV infections are in young people aged 15-24. This study concentrated on one group of young people at high risk of HIV infections, the university students. University students are quite knowledgeable in issues of HIV/AIDS, but studies have shown that utilization of HIV testing and counseling services among them is quite low. HIV/AIDS has now become an important part of the curriculum in tertiary institutions for almost all first year students15. Many countries, Kenya included, have taken steps to improve access to HIV testing and counseling services and especially among key and vulnerable populations. Despite testing uptake having generally increased, a wide and considerable gap still remains in uptake. Between 2003 and 2007, it was estimated that approximately $83 \%$ of people living with HIV/AIDS remained undiagnosed16. University students are generally expected to be more knowledgeable on HIV/AIDS issues compared to the general population. This is why this research study sought to explore on the barriers that hinder these students from utilizing HIV/AIDS testing services offered within their institutions.

\section{Conceptual framework}

This research was based on the Andersen and Newman's framework of healthcare services utilization, which aids in unmasking the conditions and factors that either facilitate or impede utilization. It is based on a basic theory that an individual's access to and use of health services is considered to be a function of three key components: Predisposing, enabling and need factors as highlighted in the diagram below.

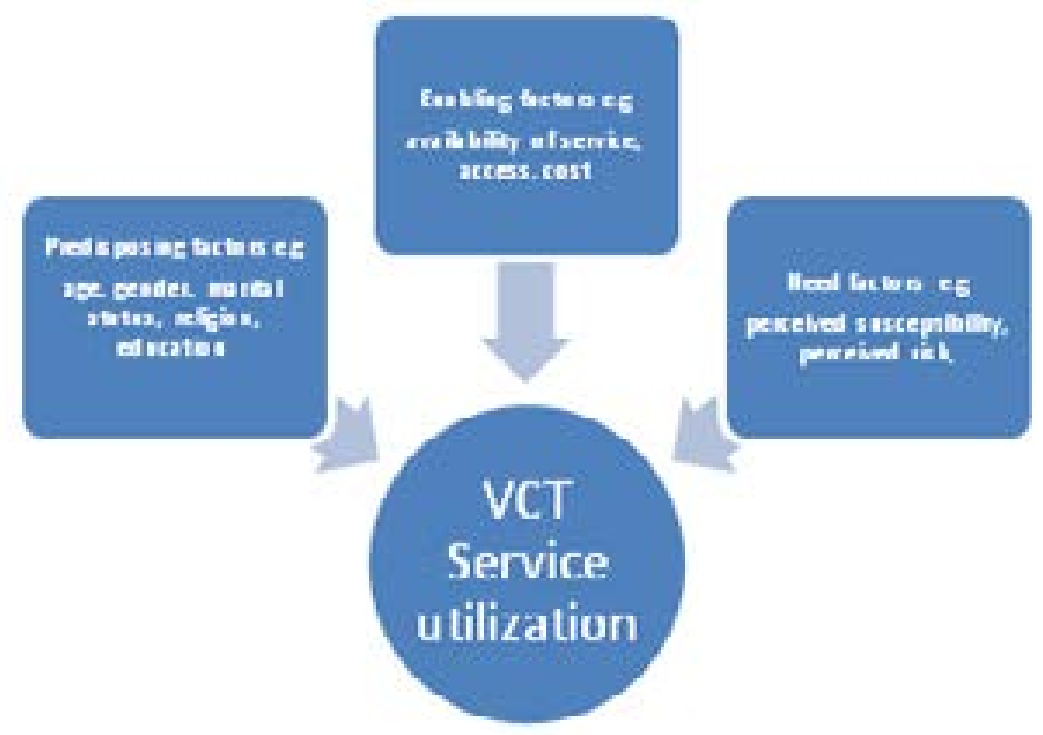

Figure 1.1: Conceptual framework of uptake of VCT services

In this study, the health service was Voluntary counseling and testing for HIV at a facility in an institution of higher learning. Given that the actual uptake and utilization of the service is lower compared to similar facilities outside the institution, then it points out that there could be some factors that either facilitate or impede the utilization of these services. 


\section{Methodology \\ Study design}

A descriptive cross-sectional study was employed where the researcher used self-administered questionnaires to collect both quantitative and qualitative data from the respondents who could read and write. Both open ended and closed ended questions were designed so as to give freedom to the respondents to write what they feel about the various components in the study. Data from VCT laboratory register at JKUAT Hospital was reviewed for the period 2010 to 2016 to give an insight into the utilization rates and patterns.

\section{Sample size and sampling method}

In this study, multi-stage sampling technique was used to select study subjects. First, with a list of the mother public Universities in Kenya, three public Universities were randomly selected. Due to variations in the student population in the selected institutions, the sample size for each was determined using population proportionate sampling PPS. Each institution was then stratified further into health science and non-health science related courses. One department in each stratum was then randomly selected and the chosen department stratified further into the various years of study to ensure that each group was represented.

The sample size was determined using the Fishers et al's formula, based on the prevalence of VCT service utilization of $38.5 \%$ during the past year among University students. Using $5 \%$ margin of error at $95 \%$ confidence level, the minimum sample size required was 246 after considering a $10 \%$ non-response rate.

Where $\mathrm{n}=$ sample size

$z=$ statistic for a level of confidence at $95 \%$ which gives a value of 1.96

$\mathrm{p}=$ expected proportion of uptake of VCT estimated at $38.5 \%$

$\mathrm{d}=$ precision with $95 \%$ confidence interval which gives a margin of error of \pm 0.05

The minimum sample size needed for the study on uptake was

$=223+23=246$

The sample size for each University was then determined using population proportionate sampling PPS technique depending on their population as shown in Table 3.1.

This was the minimum calculated sample size needed for the study. However, the researcher decided to raise the sample at JKUAT and University of Nairobi to 100 each to ensure good representativeness of the study population. The final sample size was therefore 305.

\section{Data collection}

Data collection was done with pre-tested, pre-coded, and self- administered questionnaires with open and closed ended questions. Pretesting of the instruments was conducted with a small group of students from JKUAT. The instruments were then adjusted for clarity and simplicity. The tools to be used were then assigned numerical codes to distinguish them. Having sought formal permission from the institutions selected, the principal investigator then approached the department chosen and requested for a private and convenient room, easily accessible to students and where they would comfortably fill in the questionnaires. Students were then approached and requested to participate on the study. Students were given adequate introduction on the study matter and information on how to fill the questionnaires and the principal investigator/research assistant was also present to elaborate any unclear qustions. Three focus group discussions each involving eight students from each University were conducted separately and data obtained were captured as short notes during the discussions. The participants were randomly selected during the interviews and requested to participate at own will in the discussion which was organized to the convenience and flexibility of the participants. The researcher used lottery to pick 12 maximum number of members for a FGD random numbers from the particular sample size for each institution. The researcher would then request respondents whose interviewing order corresponded to the random numbers picked to participate in a Focus group discussion. Those who consented were given further directions while for those who did not the researcher would request the next respondent. This was repeated until the desired number of members was achieved.

\section{Data analysis}

Data was cleaned, coded and entered in SPSS software version 22 for analysis. Summary statistics of independent variables were then presented using frequency tables and graphs. Odds ratios were calculated to determine the direction and strengths of association between VCT utilization and socio-demographics variables. Qualitative data were summarized according to themes related to the objectives of the study and analyzed manually. This involved 
a detailed review of the notes captured during FGD's, listing the themes engraved therein and organizing the emerging points in line with variables measured by the objectives. Results were presented in form of text, tables and graphs.

\section{Ethical considerations}

The study protocol was approved by the Kenyatta $\mathrm{Na}$ tional Hospital-University of Nairobi ethics and research committee. The researcher further sought formal permission and authority from the relevant authorities in the three Universities where data was to be collected. Informed consent was obtained and signed by those involved in the study. All data obtained were treated with high confidentiality with no identifying details being collected.

\section{Results}

\section{Demographics}

The response rate stood at 90\% with 276 respondents adequately participating in the interviews. This included $48.9 \%$ females and $51.1 \%$ males. The mean age of the respondents was 21 years. A great majority 97.1\% were single and only a few were married $2.9 \%$. The distribution across year of study was, $17.8 \%$ first years, 30.4\% second, $22.1 \%$ third, $19.6 \%$ fourth and $10.1 \%$ fifth years as illustrated in Table 3.1 below. Respondents from the health sciences made up $49.3 \%$ while $50.7 \%$ were from a non-health science department.

\section{Appendix I: Table 3.1 Sample size for selected institutions}

\begin{tabular}{|l|l|l|l|l|l|l|l|l|}
\hline University & $\begin{array}{l}\text { Student } \\
\text { population } \\
\text { Approximate }\end{array}$ & $\begin{array}{l}\text { Calculated } \\
\text { minimum } \\
\text { Sample size }\end{array}$ & $\begin{array}{l}\text { Sample } \\
\text { size used }\end{array}$ & $1^{\text {st }}$ Year & $2^{\text {nd }}$ Year & $3^{\text {rd }}$ Year & $4^{\text {th }}$ Year & $5^{\text {th }}$ Year \\
\hline University of Nairobi & 50,000 & 88 & 100 & 16 & 26 & 20 & 18 & 9 \\
\hline Kenyatta University & 60,000 & 105 & 105 & 15 & 30 & 22 & 16 & 10 \\
\hline $\begin{array}{l}\text { Jomo Kenyatta University of } \\
\text { Agriculture and Technology }\end{array}$ & 30,000 & 53 & 100 & 18 & 28 & 19 & 20 & 9 \\
\hline \multicolumn{2}{|c|}{} & $\mathbf{2 4 6 + 1 0 \%}$ & $\mathbf{3 0 5}$ & $\mathbf{4 9}$ & $\mathbf{8 4}$ & $\mathbf{6 1}$ & $\mathbf{5 4}$ & $\mathbf{2 8}$ \\
\hline
\end{tabular}

\section{Uptake of HIV testing and counseling services}

A majority $82.6 \%$ of the respondents had ever been tested for HIV while only a few $17.4 \%$ had never been tested. Of those who had ever taken the test, $60.5 \%$ had only been tested once while the rest 39.5\% had tested more than once. More than half $50.6 \%$ of those who had ever tested cited testing on their own volition, $24.6 \%$ tested after being persuaded by friend/relative/partner, $11.4 \%$ tested after a healthcare provider initiated the process and $11.4 \%$ tested to fulfill a requirement. The results also showed that many students $66.2 \%$ took the test more than three months ago while only a few $33.8 \%$ were tested in the last three months.

\section{Awareness on VCT}

Of the 276 respondents in the study, 97.1\% of them were aware of VCT services while only $2.9 \%$ have never heard of VCT services. Of those who are aware of VCT services, $79.1 \%$ had ever tested in a VCT and the rest $20.1 \%$ had never used a VCT. When asked whether they were aware of the presence of a VCT on campus, $84.4 \%$ affirmed while $15.6 \%$ had never heard of a VCT on campus. Of those aware of the VCT being available on campus, only $45.1 \%$ had ever utilized it's services, while $54.9 \%$ have never gone there for testing and counseling. When asked whether one would test in a VCT on campus, $93.5 \%$ agreed while $6.5 \%$ stated they would not.

\section{Model of testing}

Mobile testing and counseling seems to be the most popular $50.4 \%$, followed by provider initiated testing and counseling $25.7 \%$, self-testing $12.7 \%$ and Moonlight testing and counseling $11.2 \%$. When asked on the effect of the model of testing on uptake, a majority $79.3 \%$ of the respondents agreed that the model does affect uptake of the services while $20.7 \%$ were convinced it does not.

The researcher also sought to find out what was the desired characteristic of a VCT facility on campus. As seen from the results in Table 4.1 below, a great majority of the students desire a VCT facility in the University to possess characteristics such as being easily accessible, being separately placed from other health services, being mobile/ stand alone, one that encourages self-testing and one that operates even past working hours. These seem to be the most desired characteristics in a VCT facility on campus. 


\section{Appendix II: Table 4.1 Desired characteristic of a VCT on campus}

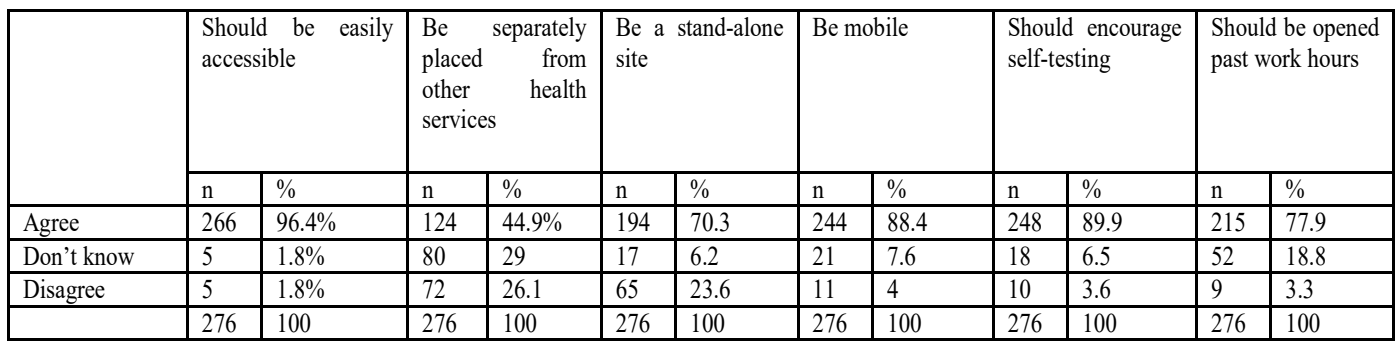

From past studies, the researcher selected four key factors that have been frequently reported to be at play in determining uptake and utilization of VCT services among young people.

Data captured on the Table 4.2 below shows the extent to which the stated factors could affect uptake of testing services in VCT facilities in institutions of higher learning as reported by the respondents.

Association between socio-demographics of respondents and uptake of services
Cross-tabulation was done and odds ratios calculated to show both the direction and strength of the associations. As seen from Table 4.3, age category, marital status and year of study proved significantly associated with uptake of services. There was no association found between gender, religion and department and uptake of services. It is only in the case of department of study whereby students from the non-health science department were 1.38 times likely to test compared to those from the health science department.

Appendix III: Table 4.2 Factors associated with testing

\begin{tabular}{|c|c|c|c|c|c|c|c|c|}
\hline & \multicolumn{2}{|c|}{ Fear to be seen at site } & \multicolumn{2}{|c|}{ Fear of test result } & \multicolumn{2}{|c|}{$\begin{array}{ll}\text { Accessibility of } \\
\text { testing site }\end{array}$} & \multicolumn{2}{|c|}{ Testing hours } \\
\hline & $\mathrm{n}$ & $\%$ & $\mathrm{n}$ & $\%$ & $\mathrm{n}$ & $\%$ & $\mathrm{n}$ & $\%$ \\
\hline To a great extent & 134 & 48.6 & 166 & 60.1 & 219 & 79.3 & 174 & 63 \\
\hline To a some extent & 105 & 38 & 91 & 33 & 51 & 18.5 & 83 & 30.1 \\
\hline To a lesser extent & 28 & 10.1 & 16 & 5.8 & 5 & 1.8 & 8 & 2.9 \\
\hline To no extent & 9 & 3.3 & 3 & 1.1 & 1 & 0.4 & 11 & 4 \\
\hline & 276 & 100 & 276 & 100 & 276 & 100 & 276 & 100 \\
\hline
\end{tabular}

\section{Appendix IV: Table 4.3 Measures of association between socio demographic factors and uptake of VCT services in institutional facilities Odds Ratios}

\begin{tabular}{|c|c|c|c|c|c|c|}
\hline Factor & Category & Tested & $\begin{array}{ll}\text { Did } & \text { not } \\
\text { Test } & \end{array}$ & Odds ratio & $\begin{array}{l}\text { 95\% Confidence } \\
\text { Interval }\end{array}$ & p-value \\
\hline \multirow[t]{2}{*}{ Age category } & $17-20$ & 50 & 104 & \multirow[t]{2}{*}{0.58} & \multirow[t]{2}{*}{$0.36,0.96$} & \multirow[t]{2}{*}{0.0327} \\
\hline & $21-24$ & 55 & 67 & & & \\
\hline \multirow[t]{2}{*}{ Gender } & Male & 51 & 84 & \multirow[t]{2}{*}{0.98} & \multirow[t]{2}{*}{$0.6,1.59$} & \multirow[t]{2}{*}{0.9291} \\
\hline & Female & 54 & 87 & & & \\
\hline \multirow[t]{2}{*}{ Marital status } & Single & 99 & 169 & \multirow[t]{2}{*}{0.2} & \multirow[t]{2}{*}{$0.04,0.99$} & \multirow[t]{2}{*}{0.0481} \\
\hline & Married & 6 & 2 & & & \\
\hline \multirow[t]{2}{*}{ Department } & Health-science & 57 & 79 & \multirow[b]{2}{*}{1.38} & \multirow[b]{2}{*}{$0.85,2.25$} & \multirow[t]{2}{*}{0.1926} \\
\hline & $\begin{array}{l}\text { Non health- } \\
\text { science }\end{array}$ & 48 & 92 & & & \\
\hline \multirow[t]{2}{*}{ Year of study } & Junior $1^{\text {st }} \& 2^{\text {nd }}$ & 44 & 89 & \multirow[t]{2}{*}{0.37} & \multirow[t]{2}{*}{$0.23,0.6$} & \multirow[t]{2}{*}{0.0001} \\
\hline & Senior $3^{\text {rd }}, 4^{\text {th }} \& 5^{\text {th }}$ & 82 & 61 & & & \\
\hline \multirow[t]{2}{*}{ Religion } & Christian & 78 & 139 & \multirow[t]{2}{*}{0.67} & \multirow[t]{2}{*}{$0.87,1.19$} & \multirow[t]{2}{*}{0.1699} \\
\hline & Other & 27 & 32 & & & \\
\hline
\end{tabular}


The researcher was able to review data from the VCT at JKUAT hospital for 6138 cases who accessed the facility during the period 2010-2016 with the aim of gaining an insight into the utilization rates and the possible reasons that motivated the students to seek the services in the facility. Data review at VCT facilities in both Kenyatta University and The University of Nairobi was not feasibly possible due to procedural bureaucracies as the researcher was only allowed to interview students. Detailed information captured by the counselors in the 'Remarks' section of the JKUAT Hospital's HIV testing and counseling HTC laboratory register gave an insight into the several reasons why students sought testing and counseling services. These reported reasons were categorized and tallied as they appeared in the register excluding cases with no comments made about them. Emerging themes from the study indicate that participants utilized the services for different reasons as summarized in Table 4.4.

\section{Appendix V: Table 4.4 Reasons associated with testing as seen in VCT Data JKUAT Hospital}

\begin{tabular}{|l|l|l|}
\hline Factor & Frequency n & Percentage \% \\
\hline Multiple sexual partners & $\mathbf{5 8 8}$ & $\mathbf{3 8 . 9}$ \\
\hline Getting into/out of relationship & $\mathbf{2 3 4}$ & $\mathbf{1 5 . 4}$ \\
\hline Recently engaged in a risky behavior & $\mathbf{1 9 5}$ & $\mathbf{1 2 . 9}$ \\
\hline Exposure after drinking, with sexual worker/sodomy & $\mathbf{1 5 8}$ & $\mathbf{1 0 . 4}$ \\
\hline Testing upon request by partner & $\mathbf{8 7}$ & $\mathbf{5 . 7}$ \\
\hline Feeling unwell & 71 & 4.7 \\
\hline Routine testing as couple & 49 & 3.2 \\
\hline $\begin{array}{l}\text { Seeking post exposure prophlaxis after } \\
\text { condom bursts }\end{array}$ & 47 & 3.1 \\
\hline Partner declines to be tested & 42 & 2.8 \\
\hline Pregnancy & 13 & 0.9 \\
\hline Travel abroad & 12 & 0.8 \\
\hline After an alleged rape & 7 & 0.5 \\
\hline Ex-girlfriend recently tested positive & 6 & 0.3 \\
\hline Need family planning information & 3 & 0.2 \\
\hline Accident/stabbed & 3 & 0.2 \\
\hline
\end{tabular}

\section{Themes from FGD's}

Three focus group discussions were held at the three Universities. Each FGD had 8 members who were students selected randomly during the interviews. After carefully reviewing the notes taken during the discussions, emerging themes were listed under the main variables measured by the objectives of the study. Analysis of the data collected during the FGD's also yielded relatively similar findings with regard to the factors associated with uptake of testing and counseling services in institutional VCT facilities. Key reasons identified included:

-Being in a relationship- One participant from Kenyatta University noted "Those who go to the VCT in one way or another must be in a relationship and are probably sexually active. I know of friends who have insisted to their boyfriends to start the relationship with going for a VCT test. Of course the University VCT was close by, and so they got tested." This point was repeatedly mentioned as another JKUAT student pointed out "My girlfriend is the one who convinced me to visit the campus VCT, alone, I would have seen no need of testing actually."

-Desire to know one's HIV status- A participant commented that "Most people have become aware of the need and importance of knowing their own status. Especially if friends around you all claim to know their status, this pesters you until you are like, well, why not test anyway." Another student participant had this to say, "There has been a lot of campaign about 'Jua hali yako' Know your status in the media and this I guess has made most of us see the need of knowing our HIV status"

-Feeling unwell- A young lady, 22, noted that "You see if you fall ill, and you haven't been tested for HIV, the first thing that comes to your mind is to test and exclude HIV from the equation. 
I bet most students who fall ill start at the VCT in the University before seeking further diagnosis." This point was repeatedly mentioned in all the discussions. A student participant at the University of Nairobi noted that "Currently whenever you visit the bealth facility they ask you to go through the VCT first. So when one gets ill you have no other choice but to go see a counselor, not a good approach though."

-Testing for fun- A male participant noted, "Some of my classmates are really daring and brag about their HIV statuses. So this sometimes makes us to go out as a group to just test for fun, though at times its not easy." This seems to be particularly observed mostly in males, as another JKUAT student participating in the discussion had to say, "It is always fun to visit the campus VCT as a group, though the mood that sets in when you get there is not fun any longer. But the whole experience is positive, especially when the test turns out pretty good for you."

-Engaging in risky sexual behaviors- One participant noted that "You see if you mess up when you are drunk after a night out or if you have had this girlfriend of yours and you don't know each other's status, it keeps ticking on you that you need to test, until you just give in and go to the VCT." The same observation was made by a female participant from Kenyatta University who noted "Why would someone who doesn't 'play around" need to test for HIV, in one way or the other, seeking testing and counseling goes hand in hand with that."

\section{Discussion}

Recognizing the importance of voluntary HIV testing and counseling in mitigating the impacts of HIV/AIDS, especially among the youths, this study sought to determine the factors associated with uptake and utilization of these services among students aged 18-24 years, in public universities in Kenya. Uptake of VCT services by university students has been reported to be low4. The findings from this study indicatedspan style="font-family:'Times New Roman'" > that uptake of institutional VCT services stood at $45 \%$. Whereas $84.4 \%$ of students were aware of the presence of these services on their campuses, only $45 \%$ of them had ever utilized them. These findings resonate with those of a previous HIV/AIDS assessment from a representative sample of 1,917 university students at Moi University in Eldoret, where rates of voluntary counseling and testing were low ${ }^{13}$.

Knowledge of VCT seems to directly affect uptake since those with knowledge of VCT on campus reported a higher uptake. More so, the model of testing also is as- sociated with its uptake. $90 \%$ of the study respondents reported that the model of testing does affect its uptake. That a high portion $50.4 \%$ of the respondents are familiar with the mobile testing and counseling model could be an indicator of its higher uptake.

The findings concur with those in a study done by Njagi and Maharaj ${ }^{17}$, where students who felt being at an elevated risk of HIV infection took up the services more. Another research done in South Africa indicated the rise of transactional and inter-generational sex, predation and multiple sexual partners as a big challenge among university students 8 . These and other risky sexual behaviors seem to push students to seek VCT services so as to know their statuses.

Age is another factor that can be associated with uptake of services. As seen from the data reviewed, as students age they seem to utilize the services more. Comparing uptake among the ages 17-19 and 20-24, the older category appear to utilize the services in a higher numbers. As seen in table 4.3, odds ratios showed significant association between age category and uptake of services. These findings agree with Okonkwo et al's study findings in Nigeria that reported younger people as seeking testing services compared to the older group ${ }^{18}$. These findings still resound in a national population-based study in Zimbabwe which revealed an inverse association between age and HIV testing ${ }^{19}$.

Gender is another factor that seemed to affect uptake of VCT services among students. Though the findings did not prove to any significant association, it revealed that more males than females utilized the services. However, findings from this study contradict those of Obemeyer \& Osborn 2007, which found that men tend to underestimate their risk to HIV infection than do women ${ }^{20}$. However, as seen from the descriptive statistics on data reviewed from JKUAT Hospital VCT, more males seem to utilize services more than their female counterparts. That can be explained by the fact that more males seem to encourage themselves to test in groups than do females, and hence their higher prevalence in testing. The findings from focus group discussions during the study hammered this theme more. Participants explained how males in groups dare each other to go and find out their statuses together. This results in a higher number of males taking up the services. Similarly, a national population-based survey in Zimbabwe revealed that among those who had been 
tested, men $53 \%$ were more likely than women $33 \%$ to voluntarily test for $\mathrm{HIV}^{20}$. The study also revealed that, in contrast, $46 \%$ of women who had been tested reported provider-initiated testing compared to $27 \%$ of men. It therefore appears that with regards to testing voluntarily, the males readily take up the services more compared to their female counterparts.

\section{Year of study}

The data also showed significant association between the year of study of the respondents and uptake of VCT services. This can be explained by the observation where more students aged 17-20 utilized the services more than their older counterparts. This is therefore a common observation for both age category and year of study as the older students are most likely in their senior years while the younger are in the junior years of study.

\section{Marital status}

The results also showed significant association between marital status and uptake of services among students. This is however an expected observation since most students within the age category 17-24 are not married and hence the observation.

Other factors also seem to be associated with uptake and utilization of VCT services in institutional facilities. These are; accessibility, testing hours, and mobility of the testing facility. Majority $96 \%$ students who responded to the questionnaires reported that accessibility of the testing facility can affect to a great extent the utilization of services. Similar findings were found among Malawian and Ugandan youth ${ }^{21}$. A study by Angotti, Bula, Gaydosh, Kimchi, Thornton and Yeatman 2009 in Malawi also found that respondents favored door-to-door testing because it was convenient ${ }^{22}$. Door-to-door testing removed the obstacle of travel, which is time-consuming and costly. Travelling to reach a health facility imposes both a direct cost for a mini-bus or bicycle rental, but also the opportunity of costs of hours travelling and waiting to be seen by a health care provider ${ }^{23}$. This could be attributed to either cost of travel or the time taken to access the facilities and also the time taken to return to places of residence. It is therefore evident that facilities within reach to students can translate into more uptakes of the services offered.

\section{Conclusion}

University students seek and utilize services for different reasons and in differing patterns. Generally in the age category 18-24, students in the lower age group 18-21 utilize VCT services more than their older counterparts. The male students also seem to seek testing more than the females, a pattern explained by the fact that more males access VCT facilities as groups rather than alone. A great majority of students reported accessibility, testing hours and fear to be seen at testing site as the main factors that affect to a great extent uptake and utilization of VCT services. It is therefore clear that there are barriers and enhancers to service utilization among University students.

\section{Study limitation}

Inaccessibility to VCT records in two of the sampled Universities was one drawback in the study.

\section{Recommendations}

It is necessary for policy makers in institutions of higher learning together with those tasked with managing healthcare services in these institutions to adopt approaches that will overcome the barriers to utilization of VCT services among students. With knowledge of the factors associated with uptake and utilization of VCT services in institutional facilities, efforts to tackle the barriers and maximize on enhancers should be utilized fully in order to improve uptake and utilization of services. More research should also focus on the persisting risky sexual behaviors among University students despite the increased knowledge they have on HIV/AIDS. More so, model VCT facilities that reflect the most desired characteristics by students in Universities should be implemented to enable more students seek and access services without major barriers.

\section{Contribution to knowledge}

This study has determined that contrary to the overall poor health seeking behavior among males, those within the age category 18-24 have better health seeking behavior compared with the opposite gender.

\section{Key abbreviations}

VCT- voluntary counseling and testing

HIV/AIDS- Human immunodeficiency virus/Acquired immune deficiency syndrome

\section{Author's contribution}

All the authors were involved in the development and proofreading of the manuscript. 


\section{Conflict of interest}

The authors declare that they have no competing or conflicts of interest whatsoever. All the authors read and approved the manuscript for editing.

\section{Funding information}

This research had no external funding. All the research expenses were borne by the researchers.

\section{Ethical approval}

The project protocol was reviewed and approved by the Kenyatta National Hospital-University of Nairobi Ethics and research committee with protocol number P982/12/2016.

\section{References}

1. Joint United Nations program on HIV/AIDS UNAIDS, 2010. Report on the Global AIDS Epidemic. UNAIDS.

2. Joint United Nations program on HIV/AIDS UNAIDS, 2009. Annual Report. UNAIDS.

3. Joint United Nations program on HIV/AIDS UNAIDS, 2007. Annual Report. UNAIDS.

4. Kimanga D O, Ogola S, Umuro M, Nganga A, Kimondo L, Mureithi P. 2014. Prevalence and incidence of HIV infection, trends, and risk factors among persons aged 15-64 years in Kenya: results from a nationally representative study.

5. National AIDS Control Council NACC, Ministry of Health, Kenya, 2014. Kenya AIDS Response Progress Report.

6. Nzioka Charles, 2000. The Impact of HIV/AIDS on University of Nairobi. A report submitted to the Association for the development of education in Africa ADEA on behalf of the World Bank.

7. Fungai Mbengo. Factors influencing the use of Voluntary counseling and testing services. 2013.

8. Tamara Shefer, Lindsay Clowes, Tania Vergnani. 2012. Narratives of transactional sex on a university campus.

9. Joint United Nations program on HIV/AIDS UNAIDS, 2014. Construction of core indicators for monitoring the 2011 political declaration on HIV/AIDS, Global AIDS response progress report.

10. Magu D G. 2015. Association between substance abuse and HIV/STI risky sexual related behaviors among students in selected public Universities, Kenya.

11. National AIDS and STI Control Program NASCOP, Ministry of Health, Kenya, 2015. The Kenya HIV Testing and counseling services guidelines.

12. Caleb J Othieno, Roselyne Okoth, Karl Peltzer, Supea Pengpid and Lucas O Malla. 2015. Risky HIV sexual behavior and depression among University of Nairobi students.

13. Mary B Adam, Mike Mutungi. 2007. Sexual risk behavior among Kenyan University students. Journal of the Arizona-Nevada Academy of science.

14. Kenya National Bureau of statistics and ICF Macro. Kenya Demographic and Health Survey, 2008-2009.

15. Kitila Mkumbo. 2013. Assessment of HIV/AIDS knowledge, attitudes and behaviours among students in higher education in Tanzania.

16. National AIDS Control Council NACC and National AIDS and STI Control Program NASCOP, Ministry of Health, Kenya, 2014. Kenya HIV estimates report. Nairobi, 2014.

17. Njabulo Nkomazana and Prantha Maharaj. 2014. Perception of risk of HIV infections and sexual behavior of the sexually active University students in Zimbabwe.

18. Sambisa W., Curtis S., and Mishra V. 2010. AIDS stigma as an obstacle to uptake of HIV testing: evidence from a Zimbabwean national population-based survey. 19. Okonkwo KC, Reich K, Alabi AI, Umeike N, Nachman SA. Evaluation of awareness, attitudes and beliefs of pregnant Nigerian women toward voluntary counseling and testing for HIV. AIDS Patient Care STDS. 2007. 20. Obermeyer, CM \& Osborn, M. 2007. The utilization of testing and counseling for HIV: a review of the social and behavioral evidence.

21. Angotti, N, Bula, A, Gaydosh, L, Kimchi, EZ, Thornton, RL \& Yeatman, SE. 2009. Increasing the acceptability of HIV counseling and testing with three Cs: convenience, confidentiality and credibility.

22. Izugbara, CO, Undie, C, Mudege, NN \& Ezeh, AC. 2009. Male youth and voluntary counseling and HIV testing: the case of Malawi and Uganda.

23. Meda Lawrence. 2013. Assessing factors influencing university students to uptake voluntary counseling and testing of HIV/AIDS 